\title{
ANALISA EFISIENSI TURBIN ANGIN BERDASARKAN VARIASI JUMLAH SUDU DI LABORATORIUM TEKNIK LISTRIK POLITEKNIK NEGERI SRIWIJAYA
}

\author{
Mutiar $^{1 / 2}$ R. Ahmad Yani ${ }^{2}$ \\ mutiar.tiar@gmail.com/ray_azhari@yahoo.co.id \\ Dosen Teknik Elektro Program Studi Teknik Listrik \\ Politeknik Negeri Sriwijaya Palembangl, \\ Dosen Tetap Yayasan pada Program Studi Teknik Elektro \\ Fakultas Teknik Universitas Palembang ${ }^{2}$
}

\begin{abstract}
ABSTRAK
Dari hasil penelitian didapat bahwa semakin besar kecepatan angin yang diberikan maka putaran turbin akan semakin tinggi sehingga daya listrik yang dihasilkan oleh generator juga akan semakin besar. Beban yang digunakan adalah beban Lampu Halogen 50W/220 V. Pada jumlah sudu turbin 12 didapatkan kecepatan putar turbin tertinggi $460 \mathrm{rpm}$ yaitu pada kecepatan $7.0 \mathrm{~m} / \mathrm{s}$ dan sedangkan jumlah sudu turbin 6 didapatkan kecepatan putar turbin tertinggi yaitu $430 \mathrm{rpm}$ yaitu pada kecepatan $7.0 \mathrm{~m} / \mathrm{s}$ juga. Untuk Efisiensi tertinggi 2,83 \% dan Efisiensi terendah yaitu 0,01\%.
\end{abstract}

Kata Kunci : Energi Angin, Turbin Angin, Pengaruh Kecepatan Angin.

\section{PENDAHULUAN}

\subsection{Latar Belakang}

Generator adalah suatu mesin listrik yang berfungsi untuk mengubah energi mekanik menjadi energi listrik. Salah satu penggerak dari generator ialah angin. Generator yang menggunakan tenaga angin menggunakan turbin angin sebagai penggerak rotor pada generator, sehingga perputaran dari rotor dipengharuhi angin yang melewati sudu-sudu dari turbin angin tersebut.

Dalam penggunaan generator angin diperlukan kecepatan angin yang optimal dan didasarkan pada tempat untuk membangkitkan daya tertentu, untuk mengoptimalkan kecepatan angin harus diketahui seberapa besar kecepatan angin. Efisiensi merupakan ukuran keberhasilan suatu kegiatan yang dinilai berdasarkan sumber daya yang digunakan untuk mencapai hasil yang diinginkan, atau efisiensi merupakan rasio dari daya output (daya listrik yang dibangkitkan) terhadap daya input (tenaga angin yang menerpa sudu turbin).

Penelitian ini menyelidiki efisiensi turbin angin. Maka dari itu penulis ingin meneliti tentang seberapa besar efisiensi daya pada turbin angin berdasarkan jumlah sudu.

\subsection{Tujuan Penelitian}

Adapun tujuan dari penelitian ini adalah sebagai berikut:

1. Untuk mengetahui besar kecepatan putar turbin dari kecepatan angin yang menerpa sudu turbin untuk menghasilkan daya input generator.

Analisa Efisiensi Turbin Angin Berdasarkan Variasi Jumlah Sudu di Laboratorium Teknik Listrik Politeknik Negeri Sriwijaya 
2. Untuk mengetahui seberapa besar daya output atau daya listrik yang dibangkitkan dari konversi kecepatan angin yang digunakan sebagai pembangkitan listrik.

\subsection{Manfaat Penelitian}

Adapun manfaat dari penelitian ini adalah sebagai berikut:

1. Dapat mengetahui besar kecepatan putar turbin dari kecepatan angin yang menerpa sudu turbin untuk menghasilkan daya input generator.

2. Dapat mengetahui seberapa besar daya output atau daya listrik yang dibangkitkan dari konversi kecepatan angin yang digunakan sebagai pembangkitan listrik.

\subsection{Ruang Lingkup Penelitian}

Penelitian dilakukan dalam dalam batasan yang berhubungan dengan hasil yang di inginkan yaitu dengan :

1. Bagaimana besar kecepatan putar turbin dari kecepatan angin yang menerpa sudu turbin untuk menghasilkan daya input generator.

2. Bagaimana besar daya output atau daya listrik yang dibangkitkan dari konversi kecepatan angin yang digunakan sebagai pembangkitan listrik.

\section{TINJAUAN PUSTAKA}

\subsection{Kecepatan Energi Angin}

Kecepatan angin yang dikehendaki untuk kincir angin berada pada kelas 3 samapai kelas 8 , dimana angin bertiup pada kecepatan angin $3 \mathrm{~m} / \mathrm{s}$ sampai $20 \mathrm{~m} / \mathrm{s}$. Indonesia belum memiliki peta angin dimana pada setiap daerah dimonitor kecepatan angin sebagai referensi untuk pembangunan kincir angin dan keperluan lainnya, seperti penerbangan. Potensi energi angin di Indonesia pada umumnya berkecepatan lebih dari 5 meter per detik $(\mathrm{m} / \mathrm{s})$. Sebagaimana diketahui menurut fisika klasik energi kinetik dari sebuah benda bermassa $\mathrm{m}$ dan kecepatan $\mathrm{v}$ adalah $\mathrm{E}=0.5 \mathrm{mv}^{2}$. Rumus tersebut berlaku juga untuk angin, yang merupkan udara bergerak.

$\mathrm{E}=\frac{1}{2} \cdot \mathrm{m} \cdot \mathrm{v}^{2}$

dimana: $\quad \mathrm{E} \quad=$ Energi (joule)

$\mathrm{m} \quad=$ Massa udara $(\mathrm{kg})$

$\mathrm{v} \quad=$ Kecepatan angin $(\mathrm{m} / \mathrm{s})$

Bilamana suatu "blok" udara, yang mempunyai penampang $\mathrm{A} \mathrm{m}^{2}$, dan bergerak dengan kecepatan $\mathrm{v} \mathrm{m/s,} \mathrm{maka} \mathrm{jumlah} \mathrm{aliran} \mathrm{massa} \mathrm{yang} \mathrm{melewati} \mathrm{suatu} \mathrm{tempat} \mathrm{adalah} \mathrm{:}$

$\mathrm{m}=\rho \mathrm{A} \mathrm{v}$

$\begin{array}{lll}\text { dimana : } & \text { A } & =\text { luas penampang }\left(\mathrm{m}^{2}\right) \\ \rho & =\text { kepadatan udara }\left(\mathrm{kg} / \mathrm{m}^{3}\right)\end{array}$

$\mathrm{P}_{\text {angin }}=\frac{1}{2} \cdot \rho \cdot \mathrm{A} \cdot \mathrm{v}^{3}$

Analisa Efisiensi Turbin Angin Berdasarkan Variasi Jumlah Sudu di Laboratorium 
dimana: $\quad \mathrm{P}_{\text {angin }}=$ Daya Angin $(\mathrm{W})$

\subsection{Turbin Angin ${ }^{[4]}$}

Sesuai dengan ketetapan Betz, sebuah turbin angin yang ideal akan mengubah 16/27(59\%) dari energi angi yang dihasilkan oleh angin. Akan tetapi dalam prakteknya daya turbin yang didapat lebih kecil karena terdapat beberapa faktor. Daya turbin angin tersebut merupakan hasil kali dari daya angin dengan coeficient performance $(\mathrm{Cp})$. Adapun rumus daya turbin adalah sebagai berikut :

$\mathrm{P}_{\text {turbin }}=\frac{1}{2} \rho \mathrm{Av}^{3} \mathrm{Cp}(\lambda, \beta)$

dimana : $\quad \mathrm{P}_{\text {turbin }}=$ daya turbin (watt)

$\mathrm{C}_{\mathrm{p}} \quad=$ koefisien performa

$\lambda \quad=$ tip speed ratio

$\beta \quad=$ sudut sudu $\left({ }^{\circ}\right)$

\subsection{Daya Generator Turbin ${ }^{[5]}$}

Daya dari generator yang dikopel langsung dengan turbin angin dapat dihitung dengan menggunakan rumus daya pada rangkaian listrik pada umumnya. Perhitungan daya juga dapat dilakukan dengan menggunakan harga dari tegangan maksimum dan arus maksimum pada gelombang sinusoidal keluaran generator yang terbentuk.

$$
\begin{aligned}
& \mathrm{P}=\mathrm{V} \times \mathrm{I} \\
& \mathrm{V}=\mathrm{V}_{\mathrm{p}-\mathrm{p}} / \sqrt{3} . \\
& \mathrm{V}=\mathrm{V}_{\mathrm{m}} / \sqrt{2} \ldots \\
& \mathrm{I}=\mathrm{I}_{\mathrm{m}} / \sqrt{2} \ldots \ldots
\end{aligned}
$$

$$
\begin{array}{ll}
\text { dimana : } & \mathrm{V}=\text { Tegangan }(\mathrm{V}) \\
& \mathrm{I}=\text { Arus }(\mathrm{A}) \\
& \mathrm{V}_{\mathrm{p}-\mathrm{p}}=\text { Tegangan Phasa ke Phasa }(\mathrm{V}) \\
& \mathrm{V}_{\mathrm{m}}=\text { Tegangan Maksimum Pada Gelombang Sinusoidal (V) } \\
& \mathrm{I}_{\mathrm{m}}=\text { Arus Maksimum Pada Gelombang Sinusoidal (I) }
\end{array}
$$

Torsi dari turbin dapat dihitung dengan rumus;

$$
\begin{aligned}
& \tau=\mathrm{Pe} / \omega \\
& \omega=2 \pi \mathrm{n} / 60
\end{aligned}
$$

Dimana : $\quad$ Pe $\quad=$ Daya Listrik Pada Beban (watt)

$$
\begin{array}{ll}
\mathrm{T} & =\text { Torsi Generator (N.m) } \\
\omega & =\text { omega }(\mathrm{rad} / \mathrm{s}) \\
\mathrm{n} & =\text { Putaran per menit (RPM) }
\end{array}
$$

\subsection{Turbin Angin Sumbu Horizontal}

Analisa Efisiensi Turbin Angin Berdasarkan Variasi Jumlah Sudu di Laboratorium Teknik Listrik Politeknik Negeri Sriwijaya 
Turbin angin sumbu horizontal (TASH) memiliki poros rotor utama dan generator listrik di puncak menara. Turbin berukuran kecil diarahkan oleh sebuah balingbaling angin (baling-baling cuaca) yang sederhana, sedangkan turbin berukuran besar pada umumnya menggunakan sebuah sensor angin yang digandengkan ke sebuah servo motor. Sebagian besar memiliki sebuah gearbox yang mengubah perputaran kincir yang pelan menjadi lebih cepat berputar karena sebuah menara menghasilkan turbulensi di belakangnya, turbin biasanya diarahkan melawan arah anginnya menara. Bilah-bilah turbin dibuat kaku agar mereka tidak terdorong menuju menara oleh angin berkecepatan tinggi.

Sebagai tambahan, bilah-bilah itu diletakkan di depan menara pada jarak tertentu dan sedikit dimiringkan. Karena turbulensi menyebabkan kerusakan struktur menara, dan realibilitas begitu penting, sebagian besar Turbin Angin Sumbu Horizontal merupakan mesin upwind (melawan arah angin). Meski memiliki permasalahan turbulensi, mesin downwind (menurut arah angin) dibuat karena tidak memerlukan mekanisme tambahan agar mereka tetap sejalan dengan angin, dan karena di saat angin berhembus sangat kencang, bilah- bilahnya bisa ditekuk sehingga mengurangi wilayah tiupan mereka dan dengan demikian juga mengurangi resintensi angin dari bilah-bilah itu.

\subsection{Turbin Angin Sumbu Vertikal}

Turbin angin sumbu vertikal/tegak ( TASV ) memiliki poros/sumbu rotor utama yang disusun tegak lurus. Kelebihan utama susunan ini adalah turbin tidak harus diarahkan ke angin agar menjadi efektif. Kelebihan ini sangat berguna di tempat-tempat yang arah anginnya sangat bervariasi. Turbin Angin Sumbu Vertikal mampu mendayagunakan angin dari berbagai arah. Dengan sumbu yang vertikal, generator serta gearbox bisa ditempatkan di dekat tanah, jadi menara tidak perlu menyokongnya dan lebih mudah diakses untuk keperluan perawatan. Tapi ini menyebabkan sejumlah desain menghasilkan tenaga putaran yang berdenyut. Drag (gaya yang menahan pergerakan sebuah benda padat melalui fluida (zat cair atau gas) bisa saja tercipta saat kincir berputar. Sudu / Blades

Untuk mendapatkan hasil yang optimal maximal dari sebuah kincir angin maka perlu diperhatikan sebagai berikut:

Bentuk sudu seperti sekerup atau memuntir, sehingga aerodinamisnya semakin baik.

- Untuk mendapatkan energi yang lebih baik sayap-sayap dipasang langsung pada rotor.

- Untuk sudu yang ideal berjumlah 3 buah sudu, karena menghasilkan pembagian gaya dan keseimbangan yang lebih baik.

\section{METODE PENELITIAN}

Metode penelitian ini dibuat untuk menjelaskan tentang penelitian yang dilakukan. Penulis melakukan pengukuran daya generator yang dihasilkan oleh generator angin terhadap kecepatan yang berbeda. Daya angin yang dihasilkan oleh blower akan menggerakkan turbin yang kemudian memutar poros dari generator sinkron yang dikopel dengan turbin tersebut. Penelitian dan pengambilan data dilakukan di Laboratorium Teknik Listrik Politeknik Negeri Sriwijaya.

\section{Langkah-langkah pengukuran:}

1. memposisikan terlebih dahulu blower dan generator angin secara berhadapan dengan jarak 1 meter.

Analisa Efisiensi Turbin Angin Berdasarkan Variasi Jumlah Sudu di Laboratorium Teknik Listrik Politeknik Negeri Sriwijaya 
2. menyiapkan Sumber AC untuk blower sebagai simulasi angin dengan menggunakan SLIDAC, atur tegangan pada SLIDAC menjadi OV terlebih dahulu kemudian hubungkan ke blower

3. Mengubah sudu generator angin yang semula mempunyai 12 sudu menjadi 6 sudu

4. Merangkai rangkaian pengukuran daya untuk generator angin sesuai dengan blok diagram rangkaian percobaan

5. Mengoperasikan blower dengan cara menekan tombol on pada blower

6. Mengukur kecepatan angin pada blower dengan menggunakan anemometer, aturlah kecepatan angin dengan mengatur tegangan sumber pada blower, aturlah sesuai dengan kecepatan angin yang telah ditentukan

7. Melakukan pengukuran untuk tegangan phasa ke phasa, arus phasa, daya total dan putaran (rpm).

\section{HASIL DAN PEMBAHASAN}

\subsection{Data Hasil Pengukuran}

Adapun Data Hasil Pengukuran Adalah Sebagai Berikut :

Tabel 4.1. Pengukuran Daya yang dibangkitkan menggunakan 12 Sudu

\begin{tabular}{|c|c|c|c|c|c|}
\hline No & Kecepatan Angin & $\begin{array}{c}\text { Jumlah } \\
\text { Sudu }\end{array}$ & $\begin{array}{c}\text { RPM } \\
(\mathrm{rpm})\end{array}$ & $\begin{array}{c}\text { Arus } \\
(\mathrm{mA})\end{array}$ & Vp-p \\
\hline 1 & $2.0 \mathrm{~m} / \mathrm{s}$ & \multirow{2}{*}{12} & 244 & $46,0 \mathrm{~mA}$ & $8,0 \mathrm{~V}$ \\
\hline 2 & $3.0 \mathrm{~m} / \mathrm{s}$ & & 284 & $58,6 \mathrm{~mA}$ & $15,0 \mathrm{~V}$ \\
\hline 3 & $4.0 \mathrm{~m} / \mathrm{s}$ & & 364 & $80,5 \mathrm{~mA}$ & $34,0 \mathrm{~V}$ \\
\hline 4 & $5.0 \mathrm{~m} / \mathrm{s}$ & & 409 & $94,3 \mathrm{~mA}$ & $49,1 \mathrm{~V}$ \\
\hline 5 & $6.0 \mathrm{~m} / \mathrm{s}$ & & 428 & $104,0 \mathrm{~mA}$ & 61,31 \\
\hline 6 & $7.0 \mathrm{~m} / \mathrm{s}$ & & 460 & $108,0 \mathrm{~mA}$ & $66,4 \mathrm{~V}$ \\
\hline
\end{tabular}

Tabel 4.2. Pengukuran Daya yang dibangkitkan menggunakan 6 Sudu

\begin{tabular}{|c|c|c|c|c|c|}
\hline No & Kecepatan Angin & $\begin{array}{c}\text { Jumlah } \\
\text { Sudu }\end{array}$ & $\begin{array}{c}\text { RPM } \\
(\mathrm{rpm})\end{array}$ & $\begin{array}{c}\text { Arus } \\
(\mathrm{mA})\end{array}$ & Vp-p \\
\hline 1 & $2.0 \mathrm{~m} / \mathrm{s}$ & \multirow{2}{*}{6} & 234 & $16,0 \mathrm{~mA}$ & $1,11 \mathrm{~V}$ \\
\hline 2 & $3.0 \mathrm{~m} / \mathrm{s}$ & & 254 & $52,2 \mathrm{~mA}$ & $8,06 \mathrm{~V}$ \\
\hline 3 & $4.0 \mathrm{~m} / \mathrm{s}$ & & 322 & $62,3 \mathrm{~mA}$ & $15,22 \mathrm{~V}$ \\
\hline 4 & $5.0 \mathrm{~m} / \mathrm{s}$ & & 401 & $76,6 \mathrm{~mA}$ & $28,20 \mathrm{~V}$ \\
\hline 5 & $6.0 \mathrm{~m} / \mathrm{s}$ & & 420 & $89,6 \mathrm{~mA}$ & $41,28 \mathrm{~V}$ \\
\hline $6 n n n n n$ & & 430 & $103,7 \mathrm{~mA}$ & $56,68 \mathrm{~V}$ \\
\hline
\end{tabular}

\subsection{Pembahasan}

\subsubsection{Daya Pada Beban}

Sesuai dengan data pengukuran percobaan dapat dilakukan perhitungan untuk nilai tahanan beban ( R Lampu ), tegangan phasa ke phasa ( V p-p ), Arus ( I), Daya ( P ), dan Torsi $(\tau)$. Beban yang digunakan adalah lampu Halogen $220 \mathrm{~V} / 50 \mathrm{~W}$ yaitu :

$$
\begin{aligned}
\mathrm{R} \text { Lampu } & =\mathrm{V} \mathrm{Lampu}^{2} / \mathrm{P} \text { Lampu } \\
\mathrm{R} \text { Lampu } & =220^{2} / 50 \\
& =968 \Omega
\end{aligned}
$$

Analisa Efisiensi Turbin Angin Berdasarkan Variasi Jumlah Sudu di Laboratorium Teknik Listrik Politeknik Negeri Sriwijaya 
Menghitung nilai tegangan phasa ke netral:

$$
\begin{aligned}
\mathrm{V} \text { p-n } & =\mathrm{Vp}-\mathrm{p} / \sqrt{3} \\
& =8,0 / \sqrt{3} \\
& =14,01 \mathrm{~V}
\end{aligned}
$$

Menghitung nilai arus yang mengalir ke beban:

$$
\begin{aligned}
\mathrm{I} & =\mathrm{Vp}-\mathrm{n} / \mathrm{R} \\
& =14,01 / 968 \\
& =0,014 \mathrm{~A}
\end{aligned}
$$

Daya yang dikonsumsi:

$$
\begin{aligned}
\mathrm{P} & =\mathrm{Vp}-\mathrm{n} . \mathrm{I} \\
& =14,01 \mathrm{~V} .0,014 \mathrm{~A} \\
& =0,196 \text { Watt }
\end{aligned}
$$
permenit :

Adapun untuk kecepatan sudut dapat dihitung berdasarkan banyaknya putaran

$$
\omega \quad \begin{aligned}
\omega & =2 \pi \mathrm{n} / 60 \\
& =2 \cdot 3,14.245 / 60 \\
& =25,6433 \mathrm{rad} / \mathrm{s}
\end{aligned}
$$

\begin{tabular}{|c|c|c|c|c|c|c|c|c|}
\hline No & $\begin{array}{c}\text { Kecepatan } \\
\text { Angin }\end{array}$ & $\begin{array}{c}\text { P angin } \\
\text { (Watt) }\end{array}$ & $\begin{array}{c}\mathrm{R} \\
(\Omega)\end{array}$ & $\begin{array}{l}\text { V p-n } \\
(\mathrm{V})\end{array}$ & $\begin{array}{c}\text { I } \\
\text { (A) }\end{array}$ & $\begin{array}{c}\Omega \\
\mathrm{rad} / \mathrm{s}\end{array}$ & $\begin{array}{c}\mathrm{T} \\
\text { (N.m) }\end{array}$ & $\begin{array}{c}\mathrm{P} \\
\text { (watt) }\end{array}$ \\
\hline 1 & $2.0 \mathrm{~m} / \mathrm{s}$ & 1,85 & \multirow{5}{*}{$968 \Omega$} & 4,67 & 0,0048 & 25,64 & 0,0008 & 0,02 \\
\hline 2 & $3.0 \mathrm{~m} / \mathrm{s}$ & 6,23 & & 9,23 & 0,0095 & 29,83 & 0,002 & 0,08 \\
\hline 3 & $4.0 \mathrm{~m} / \mathrm{s}$ & 14,77 & & 20,20 & 0,0208 & 38,20 & 0,010 & 0,40 \\
\hline 4 & $5.0 \mathrm{~m} / \mathrm{s}$ & 28,85 & & 28,52 & 0,0294 & 42,91 & 0,019 & 0,82 \\
\hline 5 & $6.0 \mathrm{~m} / \mathrm{s}$ & 49,85 & & 35,39 & 0,0365 & 45,00 & 0,028 & 1,27 \\
\hline
\end{tabular}

Daya torsi kemudian dapat dihitung seperti di bawah ini :

$$
\begin{aligned}
\tau & =\mathrm{P} / \omega \\
& =0,196 / 25,6433 \\
& =0,007 \mathrm{~N} . \mathrm{m}
\end{aligned}
$$

\subsubsection{Daya Kinetik Angin}

Untuk luas penampang yang diterpa angin dihitung seperti di bawah ini :

$$
\begin{aligned}
\mathrm{A} \quad & =\pi \mathrm{r}^{2} \\
& =3,14.0,35^{2} \\
& =0,385 \mathrm{~m}^{2}
\end{aligned}
$$

Daya angin pada kecepatan angin 2,0 $\mathrm{m} / \mathrm{s}$ kemudian dapat dihitung seperti di bawah ini :

$$
\begin{aligned}
\text { Pangin } & =\frac{1}{2} \rho A V^{3} \\
& =\frac{1}{2} \times 1,2 \times 0,385 \times 2,0^{3} \\
& =1,85 \mathrm{Watt}
\end{aligned}
$$

Tabel 4.3. Data hasil perhitungan daya generator dan daya angin pada sudu 12

Analisa Efisiensi Turbin Angin Berdasarkan Variasi Jumlah Sudu di Laboratorium Teknik Listrik Politeknik Negeri Sriwijaya 


\begin{tabular}{|c|c|c|l|l|l|l|l|l|}
\hline 6 & $7.0 \mathrm{~m} / \mathrm{s}$ & 79,16 & & 38,51 & 0,0497 & 48,67 & 0,030 & 1,50 \\
\hline
\end{tabular}

Tabel 4.4. Data hasil perhitungan daya generator dan daya angin pada sudu 6

\begin{tabular}{|c|c|c|c|c|c|c|c|c|}
\hline No & $\begin{array}{l}\text { Kecepatan } \\
\text { Angin }\end{array}$ & $\begin{array}{c}\mathrm{P} \text { angin } \\
\text { (Watt) }\end{array}$ & $\begin{array}{c}\mathrm{R} \\
(\Omega)\end{array}$ & $\begin{array}{l}\text { V p-n } \\
\text { (V) }\end{array}$ & $\begin{array}{c}\text { I } \\
\text { (A) }\end{array}$ & $\begin{array}{c}\Omega \\
\mathrm{rad} / \mathrm{s}\end{array}$ & $\begin{array}{c}\mathrm{T} \\
(\mathrm{N} . \mathrm{m})\end{array}$ & $\begin{array}{c}\mathrm{P} \\
\text { (watt) }\end{array}$ \\
\hline 1 & $2.0 \mathrm{~m} / \mathrm{s}$ & 1,85 & \multirow{6}{*}{$968 \Omega$} & 0,65 & 0,0006 & 24,59 & 0,0002 & 0,0003 \\
\hline 2 & $3.0 \mathrm{~m} / \mathrm{s}$ & 6,23 & & 4,66 & 0,0048 & 26,69 & 0,0008 & 0,02 \\
\hline 3 & $4.0 \mathrm{~m} / \mathrm{s}$ & 14,77 & & 8,79 & 0,0090 & 34,01 & 0,002 & 0,07 \\
\hline 4 & $5.0 \mathrm{~m} / \mathrm{s}$ & 28,84 & & 16,29 & 0,0168 & 42,18 & 0,006 & 0,27 \\
\hline 5 & $6.0 \mathrm{~m} / \mathrm{s}$ & 49,85 & & 23,84 & 0,0246 & 44,16 & 0,013 & 0,59 \\
\hline 6 & $7.0 \mathrm{~m} / \mathrm{s}$ & 79,16 & & 32,73 & 0,0338 & 45,73 & 0,024 & 1,10 \\
\hline
\end{tabular}

yang dibangkitkan terhadap daya input ( tenaga angin yang menerpa sudu turbin ) dengan menggunakan persamaan berikut seperti di bawah ini :

$$
\begin{aligned}
\eta_{\text {Pembangkitan }} & =\frac{\mathrm{P}_{\text {gen }}}{\mathrm{P}_{\text {mekanik }}} \times 100 \% \\
& =\frac{0,02 \times 100 \%}{1,84} \\
& =1,08 \%
\end{aligned}
$$

Tabel 4.7. Efisiensi Daya yang dihasilkan oleh generator

\begin{tabular}{|c|c|c|c|}
\hline No & Kecepatan Angin & Efisiensi 12 Blades & Efisiensi 6 Blades \\
\hline 1 & $2.0 \mathrm{~m} / \mathrm{s}$ & $1,08 \%$ & $0,01 \%$ \\
\hline 2 & $3.0 \mathrm{~m} / \mathrm{s}$ & $1,28 \%$ & $0,32 \%$ \\
\hline 3 & $4.0 \mathrm{~m} / \mathrm{s}$ & $2,70 \%$ & $0,47 \%$ \\
\hline 4 & $5.0 \mathrm{~m} / \mathrm{s}$ & $2,83 \%$ & $0,93 \%$ \\
\hline 5 & $6.0 \mathrm{~m} / \mathrm{s}$ & $2,54 \%$ & $1,18 \%$ \\
\hline 6 & $7.0 \mathrm{~m} / \mathrm{s}$ & $1,89 \%$ & $1,38 \%$ \\
\hline
\end{tabular}

\section{PENUTUP}

Dari hasil penelitian ini dapat disimpulkan adalah sebagai berikut:

1. Besar kecepatan putar turbin yang terbesar yaitu $460 \mathrm{rpm}$ pada kecepatan angin 7.0 $\mathrm{m} / \mathrm{s}$ untuk turbin dengan 12 jumlah blades. Dan kecepatan putar turbin tertinggi yaitu $430 \mathrm{rpm}$ pada kecepatan angin $7.0 \mathrm{~m} / \mathrm{s}$ untuk turbin dengan 6 jumlah blades.

2. Daya yang dibangkitkan oleh generator turbin angin pada percobaan berdasarkan perhitungan untuk beban lampu halogen $50 \mathrm{~W} / 220 \mathrm{~V}$ dengan kecepatan angin $2.0-$ $7.0 \mathrm{~m} / \mathrm{s}$ dengan jumlah sudu 12 blades adalah sebesar $0.02-1.50$ Watt sedangkan untuk sudu 6 blades memiliki daya yang lebih kecil yaitu sekitar $0.003-1.10$ Watt 


\section{DAFTAR PUSTAKA}

[1]. Bastomi, Akhwan., 2010, Simulasi Konversi Energy Angin Menjadi Energi Listrik Pada Turbin Angin Sumbu Horizontal. Malang : Universitas Islam Negeri Maulana Malik Ibrahim.

[2]. Ikhwanul Ikhsan. 2011. Analisa Pengaruh Pembebanan Terhadap Kinerja Kincir Angin Tipe Propeller Pada Wind Tunnel Sederhana.

Analisa Efisiensi Turbin Angin Berdasarkan Variasi Jumlah Sudu di Laboratorium Teknik Listrik Politeknik Negeri Sriwijaya 